\title{
The «Project Method Vs» Conventional Teaching
}

\section{Eugenia Nikolaevna Gerasimova}

Olga Alekseevna Savvina

\author{
Valentina Alekseevna Telkova
}

Roman Anatolievich Melnikov

Elena Ivanovna Trofimova

Yelets State Bunin University, 28 Kommunarov Str., Yelets, Lipetsk Region, 399770, Russian Federation

E-mail: nauka@elsu.ru

\section{Doi:10.5901/mjss.2015.v6n5s4p172}

\begin{abstract}
In recent years an interest towards the 'project method has been resumed in Russia. It was suggested by American pedagogues in the beginning of the XX century and was widely used in Soviet school in the 1920s. However, in the 1930s it was rejected. For this reason it is necessary to regard prospects for the Project Method application in the school of future having evaluated its merits and demerits in the context of modern psychological and pedagogical knowledge. As the means of psychological grounding of the project method use we review a process of forming the idea about complex intellectual operations, partly or completely un-observable, such as generalization, analysis, synthesis, etc. Theoretical research was enhanced by the experimental work of a general kind which included organizing and conducting the contest of projects on mathematics during four years on the basis of Physics and Mathematics Faculty of Bunin Elets State University. Competition results revealed new problems that must be taken into account in the organization of project activities.
\end{abstract}

Keywords: innovative and traditional forms of learning, the project method, project competition in mathematics.

\section{Introduction}

At the end of the 19th century western pedagogues focused their attention on emotional study appeal in terms if "pragmatic pedagogy". Among demerits of the existing school system the mostly claimed were: diversion from the reality, abstract, scholastic manner of teaching, etc. In order to compensate for this shortcoming, American pedagogue and psychologist John Dewey (1859-1952) suggested an idea to modernize school education, based on his practice and personal experience of the child.

Innovative ideas, expressed by J. Dewey, were developed in the works of his students and followers - American pedagogues Helen Parkhurst (1887-1973) and William Heard Kilpatrick (1871-1965) (Kilpatrik, 1918), (Parkhurst, 1922) and others. J. Dewey and W. H. Kilpatrick were colleagues as they worked at the Teachers College, Columbia University. The leading teaching method according to Dewey's concept should be the project method, due to which students create 'projects' doing practical tasks individually. The teacher acts as a consultant. He formulates the problem, directs students' activity, helps to find sources of information, etc. In this process children must plan, carry out, analyze, evaluate and solve the problem individually, i.e. be involved in the project activity.

The method is based on the idea of educational and cognitive activity of the students directed at the result which can be obtained when solving a problem having theoretical or practical value.

W.H. Kilpatrick distinguished the following stages of the project method actualized in the modern school: 1) goalsetting; 2) planning; 3) practical implementation; 4) criticism of the results.

In the practice of learning the project method was used much earlier (in 1911, the US Bureau of Education legalized the term the project method', than the famous essay by W. H. Kilpatrick "The Project Method" (1918) became a legacy of the American teaching community. The author defined this term as "hearty, purposeful act" (Kilpatrick, 1918).

In 1920s the project method was borrowed by the USSR from the American school. Apologists of the "projectbased learning" at the Soviet steel labor school were N.K. Krupskaya (1869-1939), V.N. Shulgin (1894-1965), M.V. Krupenina (1892-1950) and others. 
One of the first domestic publications on the project method was issued in 1923 in the journal "Communist Education" (Krupskaya, 1923). The article was written by N.K. Krupskaya, who paid attention to the advantages of the new method and exemplified its use in different areas. After that the books devoted to project activities into Russian began being actively translated (Kilpatrick, 1925, 1928; Collings, 1926, and others). And soon there appeared the works by national pedagogues who tried to justify the necessity and peculiarities of introduction the American experience in the Soviet school. According to V.N. Shulgin and M.V. Krupenina, the project method was the most successful to prepare the students for life, it developed "collective work and mutual assistance habit" (Ignateva et al. (Eds.), 1930). At the same time the pedagogues emphasized that implementing the project method claims for increased demands on teacher training, which must be versatile. The project method was also associated with such important merits as versatility and comprehensiveness. Pedagogues were convinced that precisely this method will contribute to the transformation of the "school of study in the school of life" to the fullest extent.

The "project method, as Y.M. Kolyagin writes, with the assistance of the theory of "school in-growth into production" began to be introduced to the Soviet school under the name of "integrated teaching method" (Kolyagin, et al., 2007). In 1923 teaching subjects in schools was rejected and a comprehensive approach for constructing curricula and training was adopted.

The comprehensive program denied systematic training, complex topics related to human nature and society were suggested for study instead of the school subjects (Mathematics, Russian Language, etc.). As a result, the students did not have a holistic view of the outside world, but received only narrow practical knowledge; education level of schoolleavers was insufficient to continue their studies at the higher educational establishments.

In the 1930s, a number of Orders by the Central Committee of the All-Union Communist Party of the Bolsheviks (b) froze the 'project method contagion in our country and until the end of the 20th century this form of schooling was not used (Abakumov et al., 1974). However, this method has been applied in the training of engineering and technical personnel.

In the second half of the 1990s a fertile ground for the resumption of project activities was created in view of the democratic transition of education and intensive development of Information and Communication Technologies. Alongside this, the attitude towards this novation nowadays in pedagogical community is not unambiguous. In particular, there is an opinion, that "traditional Project Method and school mathematics are hardly compatible issues" (Busev, 2008), that this method is not applicable to teaching exact sciences as its use often "turns to be profanation and contagious dilettantism" (Kayumov, 2014).

\section{Objectives, Methodology and Research Design}

The methodological basis for the study is the theory of the method of projects (W.H. Kilpatrick, E. Collings and others.), the ideas for sustainable correlation of traditions and innovations while training a teacher (Y.M. Kolyagin, N.K. Sergeev, V.V. Serikov and the others.), the mental image and association theory (A.M. Trofimov), the idea of critical re-evaluation of inter-civilization borrowings in pedagogy and education (O.R. Kayumov).

To achieve the objectives a set of investigation methods was used. It included: theoretical analysis of the psychical and pedagogical, regulatory and program guidance documents on the problem of the research; organization of research and experimental activities; quantitative $и$ qualitative processing of the empirical data.

The purpose of the study is to define prospects for use of the 'project method in modern school, having elicited its merits and demerits.

The study took place in three stages. The first stage included the analysis of the sources and the reconstruction of the history of the problem; a didactic support for the project competition was developed.

At the second stage annual project competitions in mathematics were held during four years, methodological support was updated and improved, project criteria for evaluation were specified, the contest results were summed up.

In 2011, the competition was attended by 60 students, in 2012 - by 55 students, in 2013 - by 57 students, in 2014 - by 47 students. Participants were divided into three age categories: students of 5-6 forms, 7-9 forms and 10-11 forms.

At the third stage the conclusions about the perspectives for applying the project in the modern school were drawn, merits and demerits of this method were brought to light, and alternative forms for the contest of students' creative works were probed.

A number of innovative teaching methods is actively implemented in modern school, in particular problem learning, integrated education, research and project education techniques (Kayumov, 2014, Sergeev, Serikov, 2013, Karpov, 2013). The process involves the pioneering teacher work as well as transition to the new federal state educational standards, which imply participant involvement in the project work, starting with the primary school. Students shall 
develop "the basics for the culture of research and project activity and skills for designing, implementing and public presentation ... of disciplinary and interdisciplinary project-based learning" [Federal State General Education Standard, 2010].

As demonstrated by the theory and practice of education, the 'project method has a number of advantages in comparison to other forms of organization of educational and research activity:

- it allows bringing pupil's learning activities closer to the practice;

- it creates the ability to work with primary sources of information and to select the necessary information for the hypothesis testing, and problem solving;

- it increases the degree of self-sufficiency of the pupil who independently discovers, interprets and applies this knowledge;

- it promotes the development of communication skills and the ability to work in a team;

- it promotes creative uptake of content.

It should be noted that, the project method is thoroughly grounded from pedagogic point of view, but still has no precise psychological grounding. In our view, the process of forming the vision of complicated intellectual operations, which are unobservable either in part or in full, in particular generalization, analysis, synthesis, etc., can act as a psychological basis for the project method. Two operations are particularly important for the project method: generalization and synthesis. Generalization is an "associative and automated assignment of qualities to the observed agent which are peculiar for other phenomena similar to this agent. Association manifestation is the main condition for carrying out generalization" (Trofimov, 2010). Of the two generalization options: involuntary and purposeful, exactly the second option is used in the learning activity. Purposeful generalization is carried out during purposeful surveillance over the outside world agents in order to gain individual knowledge, including knowledge gained not only by means of direct surveillance, but also from various information sources. Generalization provides awareness for cause-effect relationship between some properties available at any objects depending on their other properties. In the course of work with the project exactly this intellectual operation allows developing a hypothesis, which later becomes a guiding idea of the entire activity.

Project accomplishment implies formation of some mental image, and intellectual operation of synthesis plays an important role here. Synthesis is referred to when some significant characteristics of the object in question are inaccessible to perceive. The process proceeds as follows: some basis is chosen, it is usually a "psychological image of significant for an individual changes that are initiated by this process. This idea is combined by a causation component with yet non-defined images of the component parts of the process. Significant changes became the first details of the complicated process known to the researcher. ... As the research goes, the person accumulates knowledge about its cause-effect organization. ... Mental images of individual agents of the complicated process are joined to the basis by individual blocks. In the image of the complicated process formed by the block method the fact of the every separate change development is recorded twice: on one occasion every change acts as a development effect, on the other occasion as its cause" (Trofimov, 2010). This is the essence of synthesis.

It should be noted that in the course of gaining new scientific knowledge a complex use of the above intellectual operations does not always lead to the correct solution of the assigned tasks, the same can be observed in the project activities of the students, for whom carrying out a project at the same time means the process of gaining new knowledge.

When the pupil proceeds with the project, he/she has an image basis formed on the assumption of the project title and most commonly its purposes are briefly outlined by the teacher who is the project supervisor. Other elements of this image join the basis gradually. Image building difficulty lies in the fact that when introducing new ideas into the structure of this image and consolidating them one can discover incompatibility of newly suggested elements with the elements which have been already introduced to the image. At systematic study of school subjects such difficulties are partly removed by science development logic represented in the subject, centuries-long experience and established teaching methodology. There is no such well-defined structure in the project activity, joining image elements to the basis is spontaneous. Absence of abstract thinking and insufficiency of a priori knowledge do not enable a pupil to verify the image independently, which may result in the project inconsistency. And if such situation is repeated, this may predetermine formation of clipping thinking. Overcoming the above difficulties is only possible in the process of work specially organized by the teacher. For this purpose the consideration of the well-formedness level of intellectual operation in accordance with the pupil's age is the prerequisite for success of the project method application.

In connection with the advancement of the given method in the Russian school practice project competitions began to be held at different levels (Busev, 2008).

In 2011-2014 on the basis of I.A. Bunin Yelets State University there was held student mathematics project competition [16]. 
The contest invited students of 5-11 grades of general educational institutions. included:

The competition purpose was to promote mathematical knowledge among the pupils. The tasks of the contest

- to form the motivation to disclosing own creative potential of schoolchildren;

- to foster personal qualities by means of mathematics, to create the vision of the important role of mathematics in the universal culture;

- to introduce students to the facts from history of mathematics, and tendencies in the evolution of mathematical theories;

- to develop visual and figurative thinking, create ideas about the applied possibilities of mathematics;

- $\quad$ to share expertise and knowledge among students; обмен опытом и знаниями среди учащихся;

- to demonstrate capabilities of modern information and communication technologies in school mathematical education;

- to establish an electronic bank for student presentations in Mathematics, Algebra, Geometry.

A pupil's project was intended to demonstrate knowledge and skills of the pupils, their ability to work with primary sources of information, to plan and bring into effect the research work, to contrast different viewpoints, systematize and structure the gained material, generalize, and draw conclusions.

Participating in the project competition implied two stages:

1) Preparation of the application, a soft copy of the project text, presentation (followed by sending of all prepared materials to the address of the contest organizer);

2) project defense in the auditorium (among the competition participants and their scientific supervisors).

The soft copy of the project text and the presentation to be submitted to the contest must have the following set of qualities: investigative character, accomplishment independence, originality, scientific character, validity, reliability, design and presentation aesthetics, and creativity.

In the course of the project defense every competitor had to demonstrate his/her ability to explain the basic contents of the project (oral presentation culture), to use information technologies, to answer the questions and hold a discussion on the given problem.

Pupils' projects were evaluated on the following criteria: location of the educational institution (the more distant from the regional center, the higher the grade); the degree of subjective novelty of the theme for the pupils; problematicity extent; work organization logics, project presentation culture, level of saturation with mathematical apparatus, accuracy in literature use.

It was mostly important to introduce the pupils to the project evaluation criteria and evaluation system before the work begins, as this contributed to the motivational environment creation, improved work organization, understanding of its tasks and objectives.

Speaking of evaluation, the main typical merits and demerits of academic and research papers in mathematics should be highlighted. To understand the text consistency the experts proceeded from the research problem proximity (or, contrarily, remoteness) to the school program. In general the current picture is as follows: either the competitors prepared the project, based on the school program, trying to find research problem aspects which exceed this scope; or they initially used the information fairly new to them. The authors of such projects looked for the possibilities to employ new methods, theories and formulas at problem solving, known in the school mathematics course. In this case, most participants from senior school were able to formulate the project purposes, to collect, analyze and systematize the information individually in the course of the research. In our view this is the principal boundary separating the research work from the report work, which usually implies only scientific and methodical literature renew on one or another problematics. Thus, the majority of texts were not of reviewing, but individual research character.

But this virtue had a reverse side: many projects did not base on the theoretical knowledge (serious mathematical apparatus), without which it is impossible to extract adequate research problem, define objectives and tasks, choose the method of investigation in accordance with the set goal.

The experts assessed the submitted projects, selected those that met the criteria of the contest, jointly made decision to award the most interesting, coherent and competent papers.

Among the projects awarded with the diploma of I degree: "Brachistochrone Problem" (10 form), "Angular Sum of an n-Angle (various ways of proving)" (10 form), "Diophantine Equations" (10 form), "Function Graph Plotting Program Development, their Derivatives and Antiderivatives" (11 form), "Figurate numbers are interesting!" (5 form) and others.

Here are some examples of abstracts for the most successfully executed projects.

1. Trapezoid Median: which proof is better? (author - P. Chistyakova, pupil of 8th form of the Yelets Lyceum No.5) 
Mathematics differs from the other sciences as it uses proofs - a chain of deductions, proceeding from the true premises to the new conclusions. The first proofs were applied by the ancient Greek philosopher Thales in the 6th century B.C. Since then, the geometry theorems have been proved. And what is the way to understand: where to start the proof, which known mathematical facts should be applied to prove the theorem?

The proof of the trapezoid median theorem needs some additional constructions. What constructions are they? Which is easier to guess? The purpose of the project is to compare different proofs of the theorem on the trapezoid median property and highlight mathematical facts which should be used to prove this theorem.

2. Area Method (author - D. Korotkih, pupil of 11th form of the Yelets Lyceum No.5).

The notion of area is one of the key concepts in geometry. Firstly, an area is a source of geometric magnitude measurement theory, and secondly, it serves an effective tool for solving problems.

This project is devoted to the study of the area method and, consequently, various formulas and area properties. The purpose of the project is to show the possibilities of using the area method to facilitate the solution of various problems, the beauty of this method.

In the course of work over the project we have developed the formulas for area computation of arbitrary, isosceles and equilateral triangles, proved the properties relating to area as well as considered the area method application to solving problems of different levels of complexity.

3. Function Graph Plotting Program Development, their Derivatives and Antiderivatives (author - A. Sharikov, pupil of 11th form of the school No. 3 named after O.A. Morozov, the town of Efremov, Tula Region)

The study is aimed at developing a program for plotting function graphs, their derivatives and antiderivatives on the Cartesian plane. Graph plotting of functions and their derivatives, of functions and their antiderivatives on one Cartesian plane enables to clearly demonstrate their properties, to compare these properties, to establish their regularities (for instance, where the derivative graph is higher than abscissas axis, the function increases). To carry out graph plotting we had to write a program which was able to calculate the function value by the specified formula. The simplest solution was the idea of using recursion. The global variable "Xd" was used to input the function argument. String variable "fan" served as the formula input parameter.

The above projects were analyzed and evaluated by several experts, who have unanimously concluded: the project authors succeeded in adhering to the main research line. A comparison of the project text and the primary source revealed that the most of mathematical calculations were made individually. During the public defense of the projects the pupils have demonstrated a fairly high level of mathematical culture, mastery of the project subject; they answered questions clearly and correctly.

For comparison we present the excerpts from the introduction of another project, "Educational Loans" (10th form). The author conducted a survey with the pupils of our class on the question of future education:

- you are going to continue your education after school $-100 \%$ gave a positive answer

- what institution to enter $-91 \%$ of respondents plan to continue their education in technical colleges and higher educational institutions;

- if you are not enrolled in the budgetary education, do you plan to use commercial (paid) form of education $100 \%$ (of those who are going to study);

- can you afford studies regarding your family budget - only 10\% respondents can count on the family help.

The author concludes that the rest $90 \%$ of the classmates will have to meet the problem "Where to find the funds needed to pay for education?"

Further on, the author of this project formulates research goals: "to study the subject of a loan, who are the subjects for loan relations, to learn the main notions and formulas of loan calculation; to identify the difference between consumer loan and educational loan; to calculate credit payments taking into account interest repayment; to make a benchmarking assessment of the obtained result; to formulate recommendations for the enrollees about the most remunerable loan".

In the process of the paper checking it was identified, firstly, that the text contained improperly borrowed fragment of another text (plagiarism), secondly, the mathematical apparatus was used at a minimum. We could encounter only the notion "interest rate" and a several simple formulas for calculating the amount of the monthly payment on the loan. Comparative analysis stated in research task and the findings of the study looked unconvincing. As a result, the author of this project was not allowed to participate in the second stage of the competition (public defense).

During the contest the organizing committee faced several problems in its organization and conducting:

1) the announced projects included the works which reflected mathematical concepts and statements rather poorly. For example, "Mathematics and Smoking", "The Golden Section," "Lipetsk in tasks and figures", 
"Determination of the Transaction Price of a particular Apartment at a Particular Date, Based on its Equivalence with Apartments of this Type", Symmetry in the World around us";

2) the works included the projects of high scientific degree, but students were not always acquainted with the material, could not answer questions (e.g. "Mathematical Computations for Dolmen Construction Hypothesis"), which indicated that the subject choice exceeded their aging abilities.

Organizers of such competitions held in Moscow faced the similar issues. Researcher V.M. Busev testified as follows: "...All of us are familiar with this situation: search for the golden section in every conceivable and inconceivable relationships of the surrounding world (from the building of the Moscow University to poetry of M.U. Lermontov), admiration the symmetry of all things, computer presentation with a lot of optical illusions, search for mathematical harmony in electronic music... A natural question arises: where is mathematics here? Certainly, you will not ask children about this. But you can ask them something related to mathematics. For example, what is symmetry, what are some types of symmetry, what is the golden section, the Fibonacci numbers? Communication with the authors of the projects has shown that they are unable to answer any of the above questions. But at the same time they energetically talk about where to meet the golden section..." (Busev, 2008).

It would be difficult to quarrel with the opinion of V.M. Busev that as early as at the stage of setting a problem one can identify the contradiction between the project method and the school mathematics, which is primarily understood as a problem solving activity. It is supposed that a project problem must be taken from the outside world, but school tasks are distanced from life. They are either absolutely unrelated with the outside world or pseudo-practical.

In school mathematics and project activity, as the teacher fairly observes, work on the solution of the problem involves different approaches. Solving a mathematical problem requires special mental actions; preparation of the 'math' project includes collection and systematization of some information. Presentation of the results is also different. "If a pupil solved a difficult task, it is not very important how he will arrange the result: in the form of the presentation, a report or he will just scratch the solution on the checked sheet of paper. It is important that he has solved the problem. In assessing the project it is on the contrary: the problem urgency is important (for whom?) and presentation of the results (artistry and strength of the statements)" (Busev, 2008).

As a result, V.M. Busev concludes that "the traditional project method and school mathematics are hardly compatible things. However, modern Russian teachers try to combine them, understanding the project as somewhat different" (Busev, 2008).

Turning back to the project competition, we note with regret that with the course of time there has been a discernible trend of declining interest in it, themes of the projects began to reappear.

For example, from year to year there were projects on such topics: "Different Proofs of Pythagoras theorem"; "The Golden Section in Nature and Life"; "Mathematics and Art"; "Mathematics and Regional Ethnography". At the same time originality and independence of project implementation degree reduced. And there are objective reasons. Subject of the projects is restricted to the knowledge of students and teachers, so inevitably themes from year to year will be repeated. The question of how to deal with such repetition remains open. For the teacher a repeated theme does not have any novelty, but for every student who carries out a project for the first time, the same topic will be subjectively new. Obviously, this will reduce the level of independence of the pupil (or pupils), who carries out a project.

\section{Conclusions}

Having regarded academic and methodological aspects of students' project activity arrangement in the whole and issues concerning organization and holding the competition in mathematics in particular, we concluded the following:

- the analysis of the present state of the educational process showed that project activity arrangement repeats old mistakes. As in 1920s, the highest value is placed on practical activity of the pupils in projects, i.e. working on the project the students see only empirical purpose and do not replenish their academic knowledge. During four years of the scientific project competition on mathematics we constantly faced such kind of works. There is no doubt that these papers contain figures and sometimes complicated computations, but there are no new mathematical facts discovered by the pupils themselves;

- understanding the project method in the modern teaching theory and practice differs from definition of American pedagogues in the beginning of the 20th century and Soviet pedagogues in the 1920s. For example, the project in mathematics is understood as collecting information on the topic, solving usual school tasks, and even research (for example, comparison of different deduction methods of one and the same theorem). The obtained result is not always associated with life or is socially important. Until the project method does not presuppose the reconstruction of the entire education content (does not replace subject teaching), its use can 
be justified. At the same time one should not forget that breaking the education content in the 1920s (deflection of the project method into complex themes) led to decrease in the education level in the Soviet school and the 'project method failure;

- the project implementation involves the possession of mental operations such as analysis, synthesis, etc. that students can only form by a systematic study of subjects (mathematics, natural sciences, etc.), so the project method should not replace the traditional class-and-lesson and subject teaching system and can serve as a supplement to them.

Based on the above, we believe that this type of activity in the learning process should be used with great care. It is necessary to balance the project method application with the established forms and methods taking into account the traditions of Russian education and past experience.

\section{References}

Abakumov, A.A., Kuzin, N.P., Puzyrev, L.F. (Eds.) (1974). Narodnoe obrazovanie v SSSR: Obscheobrazovatelnaya shkola. [National Education in the USSR: General Academic School]: collection of documents, 1917-1973, Moscow: Pedagogika, (P. 132) [in Russian]

B.V. Ignatev and M.V. Krupenina (Eds.) (1930) Na putyakh k metodu proektov [On the way to the project method] / Collected works Moscow-Leningrad: Gosizdat (P. 224) [in Russian]

Busev, V.M. (2008). Chto takoe proekt po matematike? [What is a Project in Mathematics?] // Mathematics, No. 13 (pp.22-24) [in Russian]

Collings, E. (1926). American School Experience in the Method of Projects / Transl. from English - Moscow: New Moscow, (P. 288). [in Russian]

Federalnyiy gosudarstvennyiy obrazovatelnyiy standart osnovnogo obschego obrazovaniya (2010) [Federal State Educational Standard of General Education] // Retrieved from http://www.edu.ru/db/mo/Data/d_10/prm1897-1.pdf [in Russian]

Karpov, A.O. (2012). Metod nauchnykh issledovaniy vs metod proektov [The method of scientific research vs the project method] /I Pedagogics, No. 7, (pp.14-25) [in Russian]

Kayumov, O.R. (2014). O problemakh, svyazannyikh s mezhtsivilizatsionnyimi zaimstvovaniyami v pedagogike [On issues related to inter-civilizational borrowings in pedagogy] // Bulletin of Elets State University named after Bunin I.A., Vol. 34: A series of "Pedagogy" (History and Theory of mathematical education) - Elets, (pp.7-12) [in Russian]

Kilpatrick, W.H. (1918). The Project Method // Teachers College Record, No. 19. (pp. 319-334) [in Russian]

Kilpatrick, W.H. (1925). The Project Method. Application of concrete target in the pedagogical process. I Transl. from English Leningrad: Brockhaus-Efron [in Russian]

Kilpatrick, W.H. (1928). Foundations of method: Informal talks on teaching / Transl. from English - Moscow - St. Petersburg [in Russian]

Kolyagin, Yu.M., Savvina, O.A., Tarasova, O.V. (2007). Russkaya shkola i matematicheskoe obrazovanie: nasha gordost i nasha bol [Russian school and the mathematical education: our pride and our pain] - Oryol: Kartush (P.62) [in Russian]

Krupskaya, N.K. (1923). Metod proektov v polit-prosvetrabote [The Project Method in the Work of Political Education]. // Communist Enlightenment, No. 9, (pp. 3-10) [in Russian]

Parkhurst, X. (1922). Education on the Dalton Plan. London: Forgotten Books. 2013.

Polozhenie o konkurse uchenicheskikh proektov po matematike [Regulations on the competition of student projects in mathematics] /I Retrieved from http://www.elsu.ru/news_maem/2808-iv-konkurs-uchenicheskih-proektov-po-matematike.html

Sergeev, N.K., Serikov, V.V. (2013). Pedagogicheskaya deyatelnost v innovatsionnom obshchestve [Educational activity in the innovative society] - Moscow: Logos. [in Russian]

Trofimov, A.M. (2010). Teoriya psikhicheskogo obraza i assotsiatsiy [The theory of mental images and associations] - Elets: ESU Press [in Russian] 